\title{
Ensino Superior: a Psicologia na Formação do Nutricionista
} Higher Education: the role of Psychology in the Formation of the Nutritionist

\author{
MARIA TEREZA CUNHAALVES RIOS ${ }^{1}$ \\ MAYARACRISTINABIZIGATTO DE BRUIN² \\ PATRICIALEILADOS SANTOS ${ }^{3}$
}

\section{RESUMO}

Objetivo: identificar conteúdos de Psicologia que são abordados nos Cursos de Graduação em Nutrição e a importância atribuída por eles aos nutricionistas. Material e métodos: 60 nutricionistas de uma cidade do interior do estado de São Paulo foram entrevistados sobre conteúdos de Psicologia em seus cursos de graduação e a necessidade destes conhecimentos para atuação profissional. Procedeuse à análise qualitativa e quantitativa das informações. Resultados: Dos participantes, $71,7 \%$ tiveram apenas uma disciplina de Psicologia no curso e $64,4 \%$ consideraram que ela foi importante para sua formação. Predominaram os temas Desenvolvimento $(41,0 \%)$ e Relações Interpessoais $(35,9 \%)$. As falas dos profissionais trouxeram à tona quatro temas: 1) relação entre Nutrição e Psicologia; 2) avaliação sobre as disciplinas de Psicologia; 3) necessidades do profissional após a formação e 4) a presença da Psicologia na atuação do nutricionista. Destacam-se as falas quanto à necessidade destes conhecimentos para a atuação profissional. Conclusão: Os currículos dos cursos ainda mostram deficiências quanto a esta temática, apesar dos profissionais salientarem a importância do tema para a atuação profissional.

\section{DESCRITORES}

Ensino superior. Nutrição. Psicologia.

\begin{abstract}
Objective: To identify the contents of psychology that are covered in undergraduate courses in nutrition and the importance attributed to them by nutritionists. Material and Methods: A total of 60 nutritionists of a city in the interior of São Paulo were interviewed about contents of psychology in their undergraduate courses and the need for such knowledge to professional practice. Then we proceeded with the quantitative and qualitative analysis of the information. Results: $71.7 \%$ of the participants had only one discipline of psychology in their course and $64.4 \%$ reported that it was important to their training. Development $(41.0 \%)$ and interpersonal relationships (35.9\%) were the predominant issues. The professionals' speeches have brought to light to four themes: 1) relationship between Nutrition and Psychology; 2) assessment of psychology disciplines; 3 ) need for training after graduation; and 4) the presence of psychology in the nutritionist's performance. Of particular note are the speeches on the need for such knowledge for the professional performance. Conclusion: The curricula of the courses still have deficiencies regarding this subject, despite the fact that professionals stress the importance of the issue to their professional practice.
\end{abstract}

\section{DESCRIPTORS}

Higher Education. Nutrition. Psychology.

Nutricionista, Prefeitura Municipal de Ribeirão Preto, Secretaria da Saúde, Ribeirão Preto, SP.

2 Nutricionista. Curso de Nutrição e Metabolismo, Faculdade de Medicina de Ribeirão Preto, Universidade de São Paulo, Ribeirão Preto, SP.

3 Psicóloga, Doutora, Professor Doutor, Departamento de Neurociências e Ciências do Comportamento, Faculdade de Medicina de Ribeirão Preto, Universidade de São Paulo, Ribeirão Preto, SP. 
$\mathrm{O}$ s primeiros Cursos de Nutrição no Brasil, assim como os Cursos da área de saúde, foram planejados sob influência do modelo flexneriano, que valoriza os aspectos biológicos e individuais do ser humano, assim como a prática curativa ${ }^{1}$, desvalorizando a atenção humanista à saúde. Os currículos deste curso moldaram-se de acordo com as exigências do mercado de trabalho, e ao longo de sua existência, se caracterizaram como essencialmente técnicos e biológicos, com pouca atenção aos aspectos humanos e sociais ${ }^{2,3}$.

É possível perceber, com base nos estudos que investigam a evolução dos Cursos de Nutrição, que a necessidade atual é de criar um profissional com capacidade para integrar os diversos conhecimentos adquiridos, que tenha uma visão holística do ser humano como objeto de trabalho, que seja capaz de refletir sobre as demandas da sociedade onde vai atuar, que tenha criatividade e busque soluções para transformá-la ${ }^{1,2,4-}$ 10.

Autores destacam que para a formação de um profissional criativo, com capacidade de relacionar aspectos biológicos e sociais, é necessária justamente a presença de disciplinas da área das Ciências Humanas nos Cursos de Graduação em Nutriçãos.

Diversos estudos chamam a atenção para o fato de que os elementos básicos de trabalho do profissional nutricionista são o homem e o seu alimento, ou seja, uma relação complexa que envolve valores e significados sociais, biológicos, psicológicos, culturais, religiosos, entre outros. Portanto, a formação do nutricionista deve contemplar todas essas áreas do conhecimento ${ }^{1,5,6,8,9,11-14}$.

Em 2001, o Conselho Nacional de Educação da Câmara de Educação Superior estabeleceu as novas DCNCGN, enfatizando uma formação generalista, humanista e crítica para os nutricionistas. As diretrizes determinam que os Cursos de Nutrição incluam conteúdos das Ciências Sociais e Humanas em seus currículos, incluindo a Psicologia ${ }^{4}$. Apesar desta orientação, estudos têm apontado que as Ciências Humanas têm sido pouco valorizadas nos currículos, chegando a ocupar menos de $10 \%$ da carga horária dos cursos de Nutriçãa $0^{5,6,11}$.

Ao analisar currículos de 42 cursos de Nutrição, disponibilizados na internet pelas instituições educacionais, detectou-se que a formação ética e humanista é um dos itens menos valorizados na divulgação dos $\operatorname{cursos}^{12}$. A carga horária dedicada às Ciências Biológicas e da Saúde chega a ser três vezes mais do que aquela dedicada às Ciências Humanas e Sociais ${ }^{5}$. Há que se considerar que a formação do nutricionista requer um amplo leque de conhecimentos, dificultando, por vezes a ampliação da carga horária em humanidades.

Neste sentido, a proposição de uma carga horária mínima de 4.000 para o Curso de Nutrição, poderia favorecer a ampliação dos conteúdos de humanas e sociais e o aprimoramento dos cursos, melhorando a qualidade da formação.

O Conselho Federal de Nutricionistas (CFN) defende que a carga horária mínima do Curso de Nutrição deve ser de 4.000 horas, possibilitando uma formação de qualidade para os alunos ${ }^{1}$, confrontando a Câmara de Educação Superior do Conselho Nacional de Educação (CES/CNE) que estabeleceu uma carga horária mínima de 3.200 horas $^{15}$.

Ao encontro da opinião do CFN, outros autores também discutem sobre a ampliação da carga horária do Curso de Nutrição. Justifica-se que entre os Cursos de Saúde, o de Nutrição foi o que apresentou menor expansão da carga horária; entretanto, a ampliação da carga horária, por si só, não acarreta em melhora da formação dos alunos, sendo necessário repensar todo o modelo curricular ${ }^{16}$.

Um estudo sobre treinamento profissional no contexto de segurança alimentar e nutricional evidenciou, a partir de entrevistas com nutricionistas e docentes de cursos de Nutrição do município de São Paulo, a fragmentação dos currículos, difícultando a aproximação entre teoria e prática, bem como deficiências quanto à abordagem humanística na formação dos nutricionistas ${ }^{17}$.

Outro texto, sobre a implantação de um projeto pedagógico em um Curso de Nutrição, aponta a emergência do debate sobre as mudanças na formação no Ensino Superior, que estão acontecendo em todo o país. Dentre outras, as críticas sobre o processo de formação, foram: predomínio da visão biológica do homem; fragmentação do conhecimento; divisão da teoria e da prática, do básico e do profissionalizante ${ }^{18}$.

Existe uma carência de estudos sobre a formação dos nutricionistas e sobre suas percepções a respeito da atuação profissional que possa subsidiar uma reavaliação e reestruturação dos currículos dos cursos de graduação ${ }^{18}$. O que podemos encontrar são estudos caracterizando o perfil profissional e demográfico dos egressos deste curso ${ }^{19-22}$, e também o crescimento, a expansão e a evolução dos Cursos de Nutrição no pais, desde a sua criação até os dias atuais $^{10,22}$.

Estudo sobre a construção do conhecimento na área de Nutrição no Brasil aponta que a área de Ciências Sociais e Humanidades em Alimentação e Nutrição tem sido pouco investigada pelos pesquisadores. É possível que esta tendência seja, em 
parte, reflexo dos currículos da graduação que não têm destacado a importância destes conhecimentos para a atuação e a pesquisa em Nutrição ${ }^{23}$. Por outro lado, o avanço científico em áreas biológicas e tecnológicas também contribui para a consolidação de currículos que privilegiem tais conteúdos.

Diante deste panorama, o objetivo do presente estudo é identificar quais disciplinas e conteúdos de Psicologia são abordados nos cursos de graduação em Nutrição e como os nutricionistas avaliam esses conhecimentos, relacionando-os com a prática profissional.

\section{MATERIALEMÉTODOS}

Esse é um estudo transversal, descritivo e exploratório, com abordagem quanti-qualitativa dos dados. Para o desenvolvimento deste estudo, foram realizadas 60 entrevistas com nutricionistas da cidade de Ribeirão Preto/SP, com registro profissional, que atuam em diferentes áreas da Nutrição. As entrevistas foram feitas em locais indicados pelos entrevistados, como: local de trabalho, residência, local público, entre outros, todos dentro do município.

O contato com os nutricionistas foi feito, inicialmente, através de um convite para participação na pesquisa incluído em uma newsletter enviada pelo Conselho Regional de Nutricionistas ( $3^{\mathrm{a}}$ Região) aos profissionais registrados. Conforme foram sendo realizadas as entrevistas com os profissionais que nos contataram para participar do estudo, foi solicitado a eles que indicassem outros colegas, ampliando assim a amostra.

A entrevista foi realizada com base em um roteiro semiestruturado investigando dados sóciodemográficos, formação em nutrição e atividades profissionais, com foco nos conhecimentos da área de Psicologia aprendidos nos cursos de graduação e a necessidade de conhecimentos dessa área para a atuação profissional.

As entrevistas foram gravadas com prévia autorização dos participantes. Parte das entrevistas (23) foram transcritas na íntegra de forma a permitir uma análise para a preparação de um sistema de categorias para a análise qualitativa, seguindo as proposições da análise de conteúdo ${ }^{24,25}$. De modo complementar, foi realizado o cálculo de frequência das categorias de respostas identificadas.

Este estudo foi aprovado pelo Comitê de Ética em Pesquisa do Centro de Saúde Escola da Faculdade de Medicina de Ribeirão Preto da Universidade de São Paulo, CAAE 0023.0.175.000-10 e foi realizado em conformidade com a Resolução 466/12 do Conselho Nacional de Saúde.

\section{RESULTADOS}

Dos 60 nutricionistas entrevistados, 95\% são mulheres e 5\% são homens; as idades variaram entre 23 e 56 anos (Média =32,1 anos). Predominaram na amostra os profissionais recém-formados (Tabela 1).

Quanto à formação posterior, 85\% dos nutricionistas fez algum curso de Pós-graduação, considerando as categorias Lato Sensu e Stricto Sensu (Tabela 2).

Dos 60 entrevistados, 71,7\% comentaram que tiveram uma disciplina de Psicologia durante o Curso de Nutrição, e 26,7\% tiveram duas disciplinas. Um entrevistado não se lembrou se teve essa disciplina na graduação.

Em relação às disciplinas cursadas, a tabela 3 mostra os títulos mais citados pelos entrevistados.

Um total de 39 nutricionistas (65\%) recordaram os temas que foram abordados nas disciplinas de Psicologia. Predominaram os temas Desenvolvimento (41,0\%), Relações Interpessoais $(35,9 \%)$ e Psicanálise (20,5\%), seguidos de Transtornos Alimentares (12,8\%), Teorias da Psicologia (12,8\%), Comportamento Humano (10,3\%), Doenças Psicossomáticas (2,6\%) e Educação (2,6\%).

Dos 60 nutricionistas entrevistados, 59 falaram da importância da Psicologia na sua formação. Destes, 38 (64,4\%) consideram que as disciplinas de Psicologia foram decisivas para sua formação. Entre eles, 39,5\% justificaram que essa disciplina é importante para o nutricionista, sem acrescentar outras informações; 29\% apontam que os conhecimentos da Psicologia são importantes para auxiliar na relação nutricionista-cliente; 13,2\% destacam que a alimentação/nutrição está totalmente associada à Psicologia, por fazer parte da vida e ser afetada pelo estado psicológico das pessoas e, ainda, 7,9\% apontam que a Psicologia permite compreender melhor o paciente.

Parte destes profissionais (10 profissionais dos 38), embora considere que a Psicologia foi decisiva em sua formação, destacam uma série de deficiências/falhas nas disciplinas que cursaram, como por exemplo, o momento do curso em que elas foram ministradas. $\mathrm{O}$ quadro 1 apresenta exemplos de falas que retratam esta percepção. 
"Na verdade, a gente precisa muito destas disciplinas quando a gente está na prática profissional, né? Ela pode até ser no começo, mas também o aluno precisa ir no começo para algum cenário de prática, para algum campo de estágio (...) acho que a questão da psicologia está inserida em momentos onde o aluno tem atividade prática, porque só daí ele vai entender a necessidade desta disciplina, aplicar melhor o que esta disciplina pode oferecer, e ele vai poder ter um olhar diferenciado pra aquilo que ele faz."

"Eu acho que talvez não precisaria ser logo no início da grade curricular, porque o aluno ingressante, ele não tem tanto esta maturidade de perceber que esta abordagem psicológica, vai ser importante lá na frente. Então talvez que esta disciplina pudesse ser ministrada depois do primeiro ano, quando começasse a ter algumas disciplinas mais específicas."

Quadro 1. Trecho de falas dos nutricionistas que retratam a avaliação sobre problemas quanto à disciplina de Psicologia. Ribeirão Preto, 2010.

Por outro lado, $21(35,6 \%)$ nutricionistas não consideram que as disciplinas de Psicologia foram importantes em sua formação, seja porque o curso foi muito superficial ou incompleto $(52,4 \%)$; porque não tinha nada relacionado à Nutrição $(42,9 \%)$; pelo fato desta disciplina ser ministrada no início do curso (14,3\%), ou, ainda, porque a disciplina não correspondeu às expectativas dos alunos $(4,8 \%)$.

Ao serem questionados sobre a necessidade de ter conhecimentos da área de Psicologia para a atuação profissional, 8,3\% dos entrevistados disseram que não sentem necessidade de ter esses conhecimentos para atuar. Entretanto, 91,7\% dos nutricionistas entrevistados refere que sente falta de ter mais conhecimentos da área de Psicologia para exercer a profissão. Segundo estes profissionais, os conhecimentos de Psicologia são importantes e favoráveis: ao relacionamento com pacientes/clientes e seus familiares (43,63\%); à compreensão dos pacientes/ clientes $(27,3 \%)$; para incentivar pacientes/clientes e funcionários (7,3\%); ao atendimento de indivíduos obesos e com sobrepeso $(5,45 \%)$; ao trabalho com mudança de comportamento $(5,5 \%)$; e ao atendimento de pacientes oncológicos $(1,8 \%)$. Ainda, 3,6\% destes nutricionistas enfatizaram a forte relação entre alimentação e a condição psicológica do indivíduo.

A tabela 4 revela os temas de Psicologia sugeridos para serem abordados nos cursos de Nutrição.

A partir da análise de conteúdo, observou-se que as falas dos nutricionistas se distribuíram em quatro temas: 1) relação entre Nutrição e Psicologia; 2) avaliação sobre as disciplinas de Psicologia; 3) necessidades do profissional após a formação e 4) a presença da Psicologia na atuação do nutricionista.

O tema Relação entre Nutrição e Psicologia incluiu as falas dos entrevistados, nas quais eles comentam sobre como as duas áreas estão interligadas, podendo incluir a avaliação sobre a necessidade desta relação (Quadro 2).

"O nutricionista lida o tempo todo com esta área do comportamento, então a psicologia só tem a agregar à nossa profissão."

"A relação da alimentação, dos distúrbios alimentares com o estado emocional da pessoa, é uma relação direta, não dá para a gente separar." "É necessário este conhecimento, de psicologia, justamente por ele tratar de seres humanos. Então acho que..., independente da área que ele vá atuar: nutrição clínica, ou mesmo UAN ou na Saúde Pública, ele trata de seres humanos, né? Com seres humanos. E mesmo na relação de trabalho."

"A Psicologia, em relação à saúde, é fundamental. Não tem como você trabalhar como profissional de saúde sem ter. E o paciente também precisa desse respaldo."

Quadro 2. Trechos de falas dos nutricionistas sobre a relação entre Nutrição e Psicologia. Ribeirão Preto, 2010.

O tema Avaliação das Disciplinas de Psicologia incluiu avaliações específicas da disciplina de Psicologia cursada pelos entrevistados, sendo que esta permeia julgamentos positivos e negativos, envolvendo desde a grade horária até os conteúdos ministrados (Quadro 3 ). Dos nutricionistas que falaram sobre este tópico ( 28 participantes), 10,7\% fizeram avaliações positivas a respeito das disciplinas de Psicologia cursadas e o restante avaliou negativamente as disciplinas.

"Psicologia ela pincelou alguns autores, tipo behaviorismo, sabe assim? Não era nada aplicado à Nutrição, entendeu? Nada! Não tinha aplicação nenhuma prá Nutrição, inclusive ela falava de coisas nada a ver, entendeu? Dentro da matéria dela."

"Acho que teria que ser um pouco mais aprofundado assim. Pelo menos eu tive uma 
Psicologia bem superficial. Acho que tinha que aprofundar mais o tema..."

"(...) poderia ter sido decisivo, se tivesse abordado mais conteúdo em outros anos de faculdade, porque quando a gente tá no primeiro ano e tudo é novo, eu acredito que se a gente tivesse um conteúdo maior ou que abordasse mais profundamente lá pelo terceiro ou quarto ano, eu acho que melhoraria."

Quadro 3. Trechos de falas dos nutricionistas referentes à própria avaliação sobre as disciplinas de Psicologia. Ribeirão Preto, 2010.

Já o tema Necessidade do Profissional após a Formação incluiu os relatos sobre a necessidade do profissional de Nutrição buscar mais conhecimentos tanto da Psicologia quanto da própria Nutrição (Quadro 4).

"Dentro da minha pesquisa de Mestrado, eu precisei estudar como trabalhar com grupos. Qual linha da Psicologia, se existia alguma teoria, alguma técnica própria prá trabalhos de grupo (...). Então eu fui buscar, (...) e aí eu desenvolvi técnicas de trabalho com grupos, né?"

"Quando eu comecei a trabalhar em consultório, eu comecei a perceber, assim, muito cedo, que fazia muita falta conhecer um pouco do funcionamento, do comportamento, em relação à alimentação. Eu lembro de uma menininha, que ela tinha 5 anos, era minha paciente, e ela me perguntou assim: "posso tomar coca na escola de lanche? "Ai eu discorri pra ela todos os efeitos negativos que eu sabia de coca. Ai ela virou pra mim e disse: "mas o que que eu faço com minha vontade? "E hoje, assim, até hoje, eu acho que se eu não tivesse buscado esse caminho da compreensão, um pouco da dinâmica alimentar, da relação da emoção e do comer, ouvir o que o paciente tá falando que vai além de calorias, né? Se eu não tivesse buscado isso, eu acho que meu consultório ia ser, ia ter outro rumo. Acho que contribuiu muito, mas porque eu fui percebendo que o conhecimento técnico que eu tinha de nutricionista, ele não tinha alcance (...)."

"Eu tive Psicologia, mas tive pouquinho, sabe? Eu senti falta. Durante meu processo de formação, após formada, eu, como nutricionista mesmo, eu busquei alguns grupos de estudo mesmo, que abordasse a psicologia, né? Eu sentia falta dentro da área que eu escolhi para atuar."

Quadro 4. Trechos de falas dos nutricionistas referentes à necessidade de conhecimentos sobre Psicologia após a formação. Ribeirão Preto, 2010.

A Psicologia na Atuação do Nutricionista incluiu todas as falas e comentários espontâneos feitos pelos entrevistados, referindo-se à necessidade de conhecimentos de Psicologia para realizar suas atividades enquanto nutricionistas, podendo incluir comentários destacando que este conhecimento é mais importante em alguma área específica de atuação profissional (Quadro 5).

"Por exemplo, como a gente vai convencer a pessoa a fazer, porque todo mundo sabe que fritura faz mal, comer fruta faz bem, mas como você vai convencer a pessoa a fazer isto. Isto é o que eu sinto mais dificuldade. Sabe o que tem que fazer, a gente leva esta informação, mas o que eu sinto mais dificuldade é de convencer a pessoa a cumprir nossas recomendações."

"O nutricionista tem que ter esse conhecimento, mas isto não dispensa a presença destes profissionais (psicólogo) na equipe, tem que ter! Sempre trocando ideias, um ajuda o outro."

"De repente, numa consulta você percebe que não adianta falar nada de educação nutricional, não adianta, você esquece isto porque tem outros entraves que esta comunicação não vai acontecer. Então quando a pessoa não tem essa sensibilidade, ela acaba não conseguindo fazer uma boa atuação como nutricionista, né? Então a parte da psicologia tá totalmente relacionada. (...) A partir do momento que você vá com uma visão que leva em consideração os fatores emocionais, pessoais do indivíduo que você vai tá trabalhando, acaba que tem um sucesso muito maior na nossa profissão como um todo."

Quadro 5. Trechos de falas dos nutricionistas sobre a Psicologia na atuação do Nutricionista. Ribeirão Preto, 2010. 


\begin{tabular}{|c|c|c|}
\hline Variável & $\begin{array}{l}\text { Frequência } \\
\qquad(\mathrm{N}=60)\end{array}$ & $\begin{array}{c}\text { Porcentagem } \\
\qquad(\%)\end{array}$ \\
\hline \multicolumn{3}{|l|}{ Tempo de formado } \\
\hline Menos de 5 anos & 23 & 38,3 \\
\hline Entre 5 e 10 anos & 18 & 30,0 \\
\hline $\begin{array}{l}\text { Mais de } 10 \text { anos } \\
\text { Instituição onde se graduou }\end{array}$ & 19 & 31,7 \\
\hline Particulares & 31 & 51,7 \\
\hline Públicas & 29 & 48,3 \\
\hline
\end{tabular}

\begin{tabular}{lcc}
$\begin{array}{l}\text { Tabela 2. Participação em cursos de pós-graduação. } \\
\text { Ribeirão Preto, 2010. }\end{array}$ & $\begin{array}{c}\text { Frequência } \\
\text { (N=60) }\end{array}$ & $\begin{array}{c}\text { Porcentagem } \\
\text { Curso de }\end{array}$ \\
Pós-qraduacão & 24 & 40,0 \\
\hline Lato Sensu & 10 & 16,7 \\
Stricto Sensu & 17 & 28,3 \\
Ambas & 09 & 15,0 \\
Não Fez & & \\
\hline
\end{tabular}

\begin{tabular}{lcc}
\multicolumn{3}{l}{ Tabela 3. Disciplinas de Psicologia cursadas pelos nutricionistas. Ribeirão } \\
Preto, 2010. & $\begin{array}{c}\text { Frequência } \\
(\mathbf{N}=60)\end{array}$ & $\begin{array}{c}\text { Porcentagem } \\
(\%)\end{array}$ \\
Disciplinas & 36 & 60,0 \\
\hline Psicologia & 06 & 10,0 \\
Psicologia aplicada à nutricão & 05 & 8,3 \\
Psicologia do desenvolvimento & 04 & 6,7 \\
Psicologia 1 & 04 & 6,7 \\
Psicologia 2 & 02 & 3,3 \\
Psicologia Geral & 02 & 3,3 \\
Psicologia do desenvolvimento infantil & 02 & 3,3 \\
Psicologia Social & 02 & 3,3 \\
Psicologia social e comunitária & 01 & 1,7 \\
Fundamentos da Psicologia & 01 & 1,7 \\
Elementos de Psicologia & 01 & 1,7 \\
Introducão à Psicologia & 01 & 1,7 \\
Psicologia aplicada 1 & 01 & 1,7 \\
\hline Psicologia aplicada 2 & 01 & 1,7 \\
Psicologia das relacões interpessoais & 04 & 6,7 \\
Não lembra* & &
\end{tabular}

* Não lembra o nome da disciplina ou se teve alquma disciplina de Psicoloqia. 


\begin{tabular}{lcc}
\hline \multicolumn{1}{c}{ Tabela 4. Temas sugeridos pelos nutricionistas para as disciplinas de Psicologia. } \\
Ribeirão Preto, 2010. & $\begin{array}{c}\text { Frequência } \\
\text { (N=57) }\end{array}$ & $\begin{array}{c}\text { Porcentagem } \\
\text { T\%) }\end{array}$ \\
\hline Relacões Interpessoais & 27 & 47,4 \\
Transtornos Alimentares & 14 & 24,6 \\
Obesidade, Sobrepeso & 08 & 14,0 \\
Comportamento & 07 & 12,3 \\
Motivacão & 06 & 10,5 \\
Psicologia relacionada à Nutrição & 06 & 10,5 \\
Maneio de pacientes com patologias diversas & 05 & 8,8 \\
Problemas emocionais ou comportamentais que & 05 & 8,8 \\
interferem no comportamento alimentar & & \\
Personalidade e Emoç̃̃es & 04 & 7,0 \\
Desenvolvimento & 03 & 5,3 \\
Trabalhar com arupos & 03 & 5,3 \\
Liderança participativa, coordenação & 02 & 3,5 \\
Aspectos psicológicos associados à Cirurgia & 02 & 3,5 \\
Bariátrica & & \\
Percepção corporal & 02 & 3,5 \\
Teorias da Psicologia & 02 & 3,5 \\
Psicologia Educacional & 01 & 1,8 \\
Terapia Cognitivo-comportamental & 01 & 1,8 \\
Didática & 01 & 1,8 \\
Psicologia no Tratamento Nutricional & 01 & 1,8 \\
Selecão e Treinamento & 01 & 1,8 \\
História da Psicologia & 01 & 1,8 \\
\hline
\end{tabular}

\section{DISCUSSÃO}

O número de profissionais entrevistados representa cerca de $10 \%$ dos nutricionistas do município de Ribeirão Preto (segundo informações do Conselho Regional de Nutricionistas, $3^{\mathrm{a}}$ Região) e reflete o perfil dos nutricionistas brasileiros ${ }^{19-22}$. Observa-se um grupo de pessoas jovens, em que predominam as mulheres, formadas há pouco tempo, mas já com algum curso de pós-graduação completo ou em andamento.

Há que se considerar que a Nutrição é uma profissão relativamente jovem no Brasil, com o primeiro curso sendo criado em 1939 e a regulamentação da profissão tendo ocorrido apenas em $1967^{22,26}$. Dados do Conselho Federal de Nutricionistas mostram um aumento no número de inscritos nos conselhos regionais, que subiu cerca de $400 \%$ no período entre 2000 e $2007^{26}$. A partir de 1996, com a instituição da Lei de Diretrizes e Bases da Educação (LDB), ocorreu um expressivo aumento do número de cursos de Nutrição no país. Até 1996 existiam no Brasil 45 cursos de graduação em nutrição. De 1997 a 2009 surgiram mais 346 novos cursos de nutrição no país ${ }^{22}$.
De outro lado, o perfil predominantemente feminino pode estar associado a questões culturais e à forte associação de nutrição com a atividade de cozinhar, ainda vista como uma atividade predominantemente feminina em nosso contexto ${ }^{27}$. Autores discutem essa questão e apontam algumas profissões como "ditas femininas", que articulam o trabalho profissional com o trabalho doméstico. Destaca-se que o primeiro boletim da Associação Brasileira de Nutrição, de 1959, que trazia em seu texto: "No terreno profissional, enquadra-se ele dentro de suas afinidades neutras femininas, sendo a profissão sobre muitos aspectos uma dilatação de suas atribuições domésticas. Para a mulher que não deseja seguir carreira profissional, cursos de nutrição oferecem preparo utilíssimo para o controle da economia doméstica e saúde da família"28.

No que tange à formação após a graduação, estes resultados são semelhantes aos de um estudo realizado em Ouro Preto/MG, cujo objetivo foi investigar o perfil de egressos de um curso de Nutrição, que identificou $70 \%$ de egressos com curso de pós-graduação Latu Sensu e 21,8\% com pós-graduação Stricto Sensu ${ }^{20}$. Outro estudo que investigou o perfil de nutricionistas 
brasileiros inscritos nos Conselhos Regionais de Nutricionistas, mostrou que $48,9 \%$ dos entrevistados tinham pós-graduação Lato Sensu e 15\% tinham alguma pós-graduação Stricto Sensu ${ }^{21}$.

Com relação às disciplinas de Psicologia cursadas durante o curso de Nutrição, observou-se que predominam currículos com apenas uma disciplina da área e, muitas vezes, com conteúdos considerados pouco úteis pelos nutricionistas. Apesar desta avaliação, os entrevistados conseguiram recordar os temas abordados nestas disciplinas, destacando-se os temas sobre desenvolvimento humano e relações interpessoais.

É possível que estes dois temas tenham sido mais apontados por serem também conhecimentos mais requeridos na prática profissional. Um argumento a favor desta ideia, por exemplo, é o fato de que muitos nutricionistas referiram sentir necessidade de saber mais sobre o relacionamento com os pacientes, familiares e equipe de trabalho, bem como sobre conhecer melhor o seu paciente (o que remete a conhecer também as características de desenvolvimento destas pessoas para adequar a prática profissional). Estes dados corroboram, de certa forma, recomendações da literatura sobre a importância da inserção e ampliação das disciplinas de Ciências Humanas nos cursos de graduação em Nutrição ${ }^{5}$.

Um estudo iraniano sobre as competências essenciais aos nutricionistas que atuam na saúde pública revelou, entre outras, que habilidades de comunicação, habilidades para conseguir a cooperação de outros, bem como uso de técnicas de mudança de comportamento são consideradas fundamentais pelos nutricionistas para sua prática profissional. Todas estas competências estão no arcabouço da Psicologia e vão ao encontro de necessidades destacadas pelos participantes da presente investigação. O mesmo estudo compara estes resultados com dados de outros países como Austrália, Canadá, Estados Unidos e dados europeus, mostrando resultados semelhantes quanto a tais competências ${ }^{29}$.

A importância dos conhecimentos de Psicologia na formação dos nutricionistas também é destacada pelos participantes que, apesar de muitas vezes avaliarem negativamente as disciplinas, em sua maioria afirmam que tais conhecimentos foram decisivos na sua formação profissional, apontando como argumentos para a relevância deste conhecimento a necessidade de saber se relacionar com as outras pessoas e a forte associação entre alimentação e a condição psicológica dos indivíduos. Esses resultados vão ao encontro de alguns estudos, que apontam a relação entra as condições psicológicas e emocionais do paciente e a adesão ao tratamento nutricional ${ }^{6,14}$.

A principal crítica dos participantes sobre as disciplinas de Psicologia refere-se à superficialidade com que os temas foram tratados ou à falta de conteúdo. Outra crítica importante diz respeito à falta de relação entre o conteúdo e a Nutrição. Estas informações colocam em evidência a urgente necessidade de repensar as disciplinas de Psicologia para os cursos de Graduação em Nutrição.

Uma vez que os conhecimentos da área são importantes para o exercício da profissão, eles precisam ser trabalhados de forma mais adequada, abordando temas afins à Nutrição e planejados de forma a sensibilizar o aluno para tais conteúdos, tornando-os significativos. Neste sentido, sugere-se que as disciplinas de Psicologia sejam pensadas conjuntamente por docentes Psicólogos e Nutricionistas e que os conteúdos sejam integrados às disciplinas aplicadas e aos estágios de Nutrição.

De certo modo, a crítica sobre a falta de integração dos conteúdos de Psicologia e Nutrição traz à tona uma velha discussão do ensino superior sobre a cisão entre teoria e prática e a descontinuidade entre os ciclos básico e profissionalizante $e^{30,31}$.

A análise qualitativa das entrevistas apontou que os nutricionistas a todo momento validam a ideia de que há uma forte associação entre Nutrição e Psicologia e a necessidade que estes profissionais têm de ampliar sua formação após a graduação. Esta última questão reflete, em parte, o caráter generalista da formação em Nutrição, semelhante ao que ocorre com outras profissões de saúde ${ }^{32}$ e seguindo uma tendência do ensino superior em saúde ${ }^{30}$ no Brasil.

As principais limitações do presente estudo referem-se ao tamanho da amostra e ao fato da mesma ser constituída por participantes de um mesmo município, predominando o relato sobre cursos de uma única região, o que impossibilita a generalização dos resultados.

Mais estudos são necessários sobre o tema, para que seja proposta uma reformulação nos currículos, em que as disciplinas de Psicologia sejam atreladas à prática profissional, e que seja revisto o momento do curso em que a disciplina é ministrada.

Espera-se que este estudo estimule a discussão 
e reflexão sobre os currículos e a formação em Nutrição, na direção de aprimoramento dos mesmos.

\section{CONCLUSÃO}

Os conhecimentos de Psicologia são necessários tanto para a formação quanto para a prática do Nutricionista.

As disciplinas de Psicologia estão presentes, ainda que modestamente, nos Cursos de Graduação em Nutrição, porém há críticas quanto à etapa do curso em que são ministradas e à falta de relação entre os conteúdos desenvolvidos e a prática profissional, bem

\section{REFERÊNCIAS}

1. Santos LAS, Silva MCM, Santos JM, Assunção MP, Portela $M L$, Soares MD, et al. Projeto pedagógico do programa de graduação em nutrição da Escola de Nutrição da Universidade Federal da Bahia: uma proposta em construção. Rev. Nutr. 2005; 18(1): 105-117.

2. Soares NT, Aguiar AC. Diretrizes curriculares nacionais para os cursos de nutrição: avanços, lacunas, ambiguidades e perspectivas. Rev. Nutr. 2010; 23(5): 895-905.

3. Mourão LC, Martins RCB, Vieira CM, Rossin E, L'abbate S. Análise institucional e educação: reforma curricular nas universidades pública e privada. Educ. Soc.2007; 28(98): 181-210.

4. Brasil. Ministério da Educação. Conselho Nacional de Educação. Diretrizes Curriculares Nacionais do Curso de Graduação em Nutrição. Resolução CNE/CES n 5, de 7/11/2001. Brasília: Câmara de Educação Superior; 2001.

5. Canesqui AM, Garcia RWD. Antropologia e nutrição: um diálogo possível. Rio de Janeiro: Fiocruz; 2005. p.25574.

6. Demétrio F, Paiva JB, Froes AAG, Freitas MCS, Santos LAS.A nutrição clínica ampliada e a humanização da relação nutricionista-paciente: contribuições para reflexão. Rev. Nutr. 2011; 24(5): 743-63.

7. Amorim STSP, Moreira H, Carrao TE. A formação de pediatras e nutricionistas: A dimensão humana. Rev. Nutr. 2001; 14(2): 111-18.

8. Medeiros MAT, Garcia RWD. Desafios para a capacitação no campo da alimentação e nutrição em saúde coletiva: notas preliminares. Demetra; 2013; 8(Supl.1); 349-54.

9. Medeiros MAT, Campos FCB, Moreira MIB. A integralidade como eixo da formação em proposta interdisciplinar: estágios de Nutrição e Psicologia no campo da Saúde Coletiva. Rev. Nutr., 2014; 27(6):785-98.

10. Vasconcelos FAG. A ciência da nutrição em trânsito: da nutrição e dietética à nutrigenômica. Rev. Nutr. 2010; 23(6):935-45

11. Freitas MCS, Pena PGL, Fontes GAV, Silva DO, Santos LA, Mello AO, et al. Uma leitura humanista da nutrição. In: Freitas MCS, Fontes GAV, Oliveira N. Escritas e narrativas sobre alimentação e cultura [online]. Salvador: EDUFBA, 2008. p. 208-15. como a superficialidade com que a temática é trabalhada.

As disciplinas de Psicologia foram consideradas fundamentais para a atuação do nutricionista, em especial por ajudarem em questões como: relacionamento com os pacientes e familiares, compreensão dos problemas e motivar a mudança de comportamentos.

Os currículos dos cursos ainda mostram deficiências quanto a esta temática, apesar dos profissionais salientarem a importância do tema para a atuação profissional.

A revisão dos currículos e disciplinas é emergente na busca de melhor qualificação profissional dos nutricionistas.

12. Motta DG, Oliveira MRM, Boog MCF. A formação universitária em nutrição. Pro-posições. Campinas, 2003; 14(1): 69-85.

13. Conselho Federal de Nutricionistas. Carga horária mínima para graduação em Nutrição [Internet]. Brasília: CFN; 2009 [acesso em 28 jan 2016]. Disponível em:http:// www.cfn.org.br/novosite/arquivos/PARECER-CFNCARGA-HORARIA-WORKSHOP-ENSINO.pdf

14. França $C L$, Biaginni $M$, Mudesto $A P L$, Alves ED. Contribuições da psicologia e da nutrição para a mudança do comportamento alimentar. Estudos de Psicologia. 2012; 17(2), 337-45.

15. Brasil. Ministério da Educação. Conselho Nacional de Educação. Parecer CNE/CES n² 213/2008. Dispõe sobre carga horária mínima e procedimentos relativos à integralização e duração dos cursos de graduação em Biomedicina, Ciências Biológicas, Educação Física, Enfermagem, Farmácia, Fisioterapia, Fonoaudiologia, Nutrição e Terapia Ocupacional, bacharelados, na modalidade presencial. Distrito Federal, 2008. $19 \mathrm{p}$.

16. Medeiros MAT, Santos LA, Domene SMA. Education of dietitian's in Brazil: Minimum clock hours of instruction for a bachelor's degree in nutrition. Rev. Nutr. 2013; 26(5):583593.

17. Vieira VL, Cervato-Mancuso AM. Professional training in the context of food and nutrition security. Primary Health Care Research \& Development 2015; 16: 540-544.

18. Das Neves J, Sousa AA, Vasconcelos FAG. Formação em Nutrição em Saúde Coletiva na Universidade Federal de Santa Catarina: reflexões sobre o processo de ensino para fortalecer o Sistema Único de Saúde. Ver. Nutr. 2014; 27(6):761-773.

19. Conselho Federal de Nutricionistas. Inserção profissional do nutricionista no Brasil [Internet]. Brasília: CFN; 2006. [acesso em 30 jan 2016]. Disponível em http:// www.cfn.org.br/novosite/pdf/pesquisa.pdf

20. Rodrigues KM, Peres F, Waissmann W. Condições de trabalho e perfil profissional dos nutricionistas egressos da Universidade Federal de Ouro Preto, Minas Gerais, entre 1994 e 2001. Ciênc. saúde coletiva 2007; 12(4): 1021-31. 
21. Akutsu RC. Brazilian dieticians: professional and demographic profiles. Rev. Nutr. 2008; 21(1):7-19

22. Vasconcelos FAG, Calado CLA. Profissão nutricionista: 70 anos de história no Brasil. Rev. Nutr. 2011; 24(4): 605617.

23. Vasconcelos FAG. The construction of scientific knowledge in Food and Nutrition: Analysis of dissertations and theses in the Brazilian post-graduation programs in Nutrition. Rev. Nutr. 2015; 28(1): 5-16.

24. Minayo MCS. O desafio do conhecimento: pesquisa qualitativa em saúde. São Paulo: Hucitec; 2000. 7a. ed.

25. Bardin L. Análise de conteúdo. Lisboa: Edições 70; 2003. 3a. ed.

26. Sistema Conselhos Federal e Regionais de Nutricionistas. A História do Nutricionista no Brasil [Internet] [acesso em 01 mar 2016]. Disponível em: http://www.cfn.org.br/ eficiente/repositorio/Comunicacao/Material_institucional/ 160.pdf

27. Roazzi A. Lar-doce-lar: rainha ou rei? A representação da participação masculina nas tarefas domésticas e a lógica de sua distribuição em casais de nível sócioeconômico baixo. Arq. Bras. Psicol. 1999; 51(4): 7-38.

28. Andrade LP, Lima ES. A formação e a prática do nutricionista: o gênero nas entrelinhas. Nutrire: rev. Soc. Bras. Alim. Nutr.= J. Brazilian Soc. Food Nutr. 2003 $26: 109-26$
29. Sadeghi-Ghotbabadi F, Shakibazadeh E, Omidvar N, Mortazavi F, Kolahdooz F. Consensus development on the essential competencies for Iranian public health nutritionists. Public Health Nutrition, 2014, 18(4): 752758.

30. Castanho ME. Professores de Ensino Superior da área da Saúde e sua prática pedagógica. Interface - Comunic, Saúde, Educ. 2002; 6(10):51-62.

31. Fagundes NC, Fróes Burnham T. Discutindo a relação entre espaço e aprendizagem na formação de profissionais de saúde. Interface (Botucatu) - Comunic. Saúde, Educ. 2005; 9(16):105-114.

32. Araujo D, Miranda MCG, Brasil SL. Formação de Profissionais de Saúde na Perspectiva da Integralidade. Revista Baiana de Saúde Pública.2007; 31(1):20-31.

\section{Correspondência}

Maria Tereza Cunha Alves Rios

Rua Jayme Brandão, 155. Torre 2, bloco C, ap 22. Jardim Zara.

Ribeirão Preto - São Paulo - Brasil - 14092-120

E-mail: tetehand@hotmail.com 